\title{
BMJ Open Access to palliative care by disease trajectory: a population-based cohort of Ontario decedents
}

\author{
Hsien Seow, ${ }^{1}$ Erin O'Leary, ${ }^{1}$ Richard Perez, ${ }^{2}$ Peter Tanuseputro ${ }^{3}$
}

\begin{abstract}
To cite: Seow H, O'Leary E, Perez $\mathrm{R}$, et al. Access to palliative care by disease trajectory: a populationbased cohort of Ontario decedents. BMJ Open 2018;8:e21147. doi:10.1136/ bmjopen-2017-021147

- Prepublication history and additional material for this paper are available online. To view these files, please visit the journal online (http://dx.doi. org/10.1136/bmjopen-2017021147).
\end{abstract}

Received 13 December 2017 Revised 16 February 2018 Accepted 19 February 2018

Check for updates

${ }^{1}$ Department of Oncology, McMaster University, Hamilton, Ontario, Canada

${ }^{2}$ Institute for Clinical Evaluative Sciences, McMaster University Medical Centre, Hamilton,

Ontario, Canada

${ }^{3}$ Clinical Epidemiology Program, Ottawa Hospital Research Institute, Ottawa, Ontario, Canada

Correspondence to

Dr Hsien Seow;

seowh@mcmaster.ca

\begin{abstract}
Objectives To examine access to palliative care between different disease trajectories and compare to other geographic areas.
\end{abstract}

Design A retrospective population-based decedent cohort study using linked administrative data.

Setting Ontario, Canada.

Participants Ontario decedents between 1 April 2010 and 31 December 2012. Patients were categorised into disease trajectories: terminal illness (eg, cancer), organ failure (eg, chronic heart failure), frailty (eg, dementia), sudden death or other.

Interventions Receipt of palliative care services from institutional and community settings, derived from a validated list of palliative care codes from multiple administrate databases.

Outcome measures Receiving any palliative care services in the last year of life (yes/no), intensity (total days) and time of initiation of palliative care, in hospital and community sectors. Multivariable analysis examined the association between disease trajectory and the receipt of palliative care in the last year of life.

Results We identified 235159 decedents in Ontario. In the last year of life, $88 \%$ of terminal illness, $44 \%$ of organ failure and $32 \%$ of frailty decedents accessed at least one palliative care service. Most care was provided during an inpatient hospitalisation. Terminal illness decedents received twice as many palliative care days (mean of 49 days) compared with organ failure and frailty decedents. Patients with terminal illness initiated palliative care median of 107 days before death compared with median of 19 days among those using the US Medicare hospice benefit.

Conclusions Terminal illness decedents are more likely to receive any palliative care, with increased intensity and earlier before death than organ failure or frailty decedents. These data serve as a useful comparison for other countries with similar and different healthcare systems and eligibility criteria.

\section{INTRODUCTION}

With the population ageing and living longer with more comorbidities, health systems are focused on providing quality end-of-life care through improved palliative care services. ${ }^{12}$ Earlier availability of palliative care to patients with terminal illness has been shown to improve quality of life, reduce late-life health

\section{Strengths and limitations of this study}

This study examines palliative care access and time to initiation across a comprehensive list of healthcare services by disease trajectory.

- This is a large population-based study, within a universal health system, where patients have access to both institutional and community palliative care.

- This work provides a measure of access and time to initiation to palliative care for patients in all trajectories and can be compared with other countries.

- Using administrative health data to capture use of palliative care is limited by undercoding of palliative care delivered, particularly in the community setting.

- We are unable to account for the quality of care, privately obtained care or patients' end-of-life care preferences and how those differ between trajectories.

services use and even extend survival. ${ }^{3-5}$ However, palliative care is often not delivered or initiated until very late in the dying trajectory. Research shows that dying occurs in three main trajectories: (1) terminal illness, typical of cancer (high function followed by acute decline); (2) organ failure, typical of heart and lung disease (medium-high function, intermittent acute exacerbations and partial recovery) and (3) frailty, typical of dementia (low function and prolonged gradual dwindling). ${ }^{6-8}$

Evidence shows that palliative care is more often provided to patients with cancer versus those without cancer $^{9-14}$ because of the 'predictability' of decline ${ }^{81516}$ and the history of hospice care for patients with cancer. This 'predictability' can sometimes be formalised into health policy, such as in the US Medicare Hospice Benefit, which requires a doctor's certification that death is expected within 6 months and that the patient forego any hospital or curative care. Whereas in other countries, like the UK, Australia and Canada, the eligibility criteria for palliative care does not require either condition. Given the growing body of literature of the benefits of 
early palliative care in non-cancer diagnoses, ${ }^{17-20}$ there is a dearth of research describing how access to palliative care, particularly time to initiation before death and intensity and type of service use, differs by disease trajectory, and how that may be influenced by health system and various criteria to access palliative care at a population level.

This study focuses on patients in Ontario, Canada, who can access palliative care services in community and institutional settings without foregoing curative treatment through its universal insured hospital and physician system. ${ }^{21}$ Criteria for palliative care referral in the hospital is at the physician's discretion; whereas in the community, they often use the 'surprise question' of not being surprised if the patient died within a year, ${ }^{22}$ combined with performance status decline. ${ }^{23}$ In short, eligibility in Ontario is not formally standardised, which is unlike the standardised criteria of the Gold Standards Framework, which is widespread in the UK. Ontario is the largest province in Canada and has the highest number of deaths. ${ }^{24}$ Previous studies have shown that half of patients in Ontario received at least one palliative care service in their last year of life,,$^{25}$ though they did not examine variations by disease trajectory. This study examines how disease trajectory is associated with access to palliative care services in multiple settings, including time of initiation before death and intensity and type of service use. We also compare our data to other geographic areas, namely the USA, UK and Western Australia. Our hypothesis is that compared with the USA, Ontarians will initiate palliative care services earlier, across all disease trajectories and compared with UK and Western Australia, access will be similar across all disease trajectories.

\section{METHODS}

We conducted a retrospective cohort study of Ontario decedents who died between 1 April 2010 and 31 December 2012. We used linked administrative health databases, held at the Institute for Clinical Evaluative Sciences (ICES), to identify palliative care services used across multiple health sectors in the 12 months before death. We used a previously derived comprehensive list of palliative care billing codes to capture palliative care services provided by physicians, nurses and personal support workers in multiple sectors from multiple administrate databases. ${ }^{25} 26$ The databases included: Physician claims database, which captured palliative care services billed by physicians in both community and hospital settings; Home Care Database and the interRAI databases captured publicly funded home care services, such as nursing or personal support care, with palliative care intent; Discharge Abstract Database and the National Ambulatory Care Reporting System captured hospitalisations and emergency department (ED) visits, respectively, where palliative care was the main reason for admission or consulted; Continuing Care Reporting System captured palliative care provided in long-term care and complex continuing care settings. We also linked with the Vital Statistics database for date of death, sex, age and postal code and Statistics Canada Census data for income quintile and rurality via postal codes. ${ }^{27}$

We further categorised decedents by the major trajectories of functional decline at end of life, defined by main cause of death as per prior research, ${ }^{7828}$ which have also been validated in Canada. ${ }^{29}{ }^{30}$ Using International Classification of Diseases 10th Revision codes from the death certificate as defined previously, ${ }^{29}$ decedents were classified into these trajectories: terminal illness (eg, cancer), organ failure (eg, chronic heart failure), frailty (eg, Alzheimers), sudden death (eg, accident) and other (see online supplementary appendix 1 for main causes of death).

\section{Outcomes of interest}

The primary outcome of interest was whether a decedent received palliative care at least once in the last 12 months of life. We further categorised palliative care services delivered in 'any institutional care' setting (ie, hospital inpatient, complex continuing care (analogous to subacute care), long-term care and ED) and 'any community care' settings (ie, outpatient care, home care and home-based physician billing). If both a home care and a physician home visit occur on the same day, they count as a separate home care day and separate physician home visit in subcategory analysis. However, both care events count as a single community care day in 'any community care' so as not to double count for community care that happen on the same day and count more care days than calendar days. The same definition applies to 'any institutional care'. In an acute hospital setting, palliative care days were counted for the entire duration of stay when the most responsible diagnosis for the hospital stay was palliative, palliative medicine was a service provider or a palliative service was provided. For all remaining palliative acute hospital encounters only a single day of the hospitalisation was counted (eg, patient had a postadmission palliative diagnosis). In the community-based settings of care, a palliative care day must have a record of a palliative care service in billing codes; we did not assume that care following the initiation of a palliative care code had a palliative intent in the community settings.

We also examined timing to initiation of palliative care, defined as first instance of any palliative care service captured in the last year of life. If a decedent had the first palliative care service outside of the window, initiation was represented as 365 days. We also examined intensity of palliative care by totalling the number of days palliative care was delivered, categorised by service type.

\section{Statistical analysis}

Descriptive mean and median statistics describe the usage patterns of decedents as well as the trajectory of care in the last year of life. Multivariate logistic regression was used to predict the likelihood of any use of palliative care. A negative binomial regression was used to predict the number of days of palliative care that a decedent would receive in the last year of life. Covariates included in the models include: sex, age, income quintile, rurality ${ }^{2731}$ and number 
of chronic conditions. The number of chronic conditions is derived using a combination of validated Institute for Clinical Evaluative Sciences (ICES) algorithms that use prior hospital and physician claims records to identify the disease and hospital and physician claims records in the prior 2 years before death. Ethics approval for this study was received from the Ottawa Hospital Research Institute Ethics Board in Ottawa, Canada.

\section{RESULTS}

During the study period, we identified 235159 decedents, who used a total of 4497685 days of palliative care services in the last year of life (mean 19.1 days per decedent). Our cohort was categorised into end-of-life trajectories: $32 \%$ as terminal illness, $31 \%$ organ failure, $29 \%$ frailty, $5 \%$ other and $3 \%$ as sudden death (table 1). Decedent characteristics were similar across all the trajectories, with the exception of frailty which had more older women and sudden death which had younger decedents with fewer comorbidities. Men and women were equally represented, and $80 \%$ were aged 65 years or older. Seventy-nine per cent of the cohort had three or more comorbidities, where hypertension was the most prevalent, followed by osteoarthritis, cancer, diabetes and congestive heart failure. Remaining results will focus on the three major disease trajectories: terminal illness, organ failure and frailty.

Table 1 Cohort demographics by end-of-life disease trajectory

\begin{tabular}{|c|c|c|c|c|c|c|c|c|c|c|c|c|}
\hline & \multicolumn{2}{|c|}{ Terminal illness } & \multicolumn{2}{|c|}{ Organ failure } & \multicolumn{2}{|l|}{ Frailty } & \multicolumn{2}{|l|}{ Other } & \multicolumn{2}{|c|}{ Sudden death } & \multicolumn{2}{|l|}{ Overall } \\
\hline & $\mathbf{N}$ & $\%$ & $\mathbf{N}$ & $\%$ & $\mathbf{N}$ & $\%$ & $\mathbf{N}$ & $\%$ & $\mathbf{N}$ & $\%$ & $\mathbf{N}$ & $\%$ \\
\hline Total cohort* & 75657 & 32 & 72363 & 31 & 67513 & 29 & 11784 & 5 & 7842 & 3 & 235159 & 100 \\
\hline Male & 39125 & 52 & 34371 & 48 & 30703 & 45 & 5295 & 45 & 4987 & 64 & 114481 & 49 \\
\hline Female & 36532 & 48 & 37992 & 53 & 36810 & 55 & 6489 & 55 & 2855 & 36 & 120678 & 51 \\
\hline$<19$ & 172 & $<1$ & 691 & 1 & 47 & $<1$ & 827 & 7 & 435 & 6 & 217 & 1 \\
\hline $19-44$ & 1886 & 2 & 1601 & 2 & 479 & 1 & 332 & 3 & 2636 & 34 & 6934 & 3 \\
\hline $45-54$ & 5454 & 7 & 3247 & 4 & 1738 & 3 & 442 & 4 & 1547 & 20 & 1242 & 5 \\
\hline $55-64$ & 12311 & 16 & 6631 & 9 & 4193 & 6 & 730 & 6 & 1090 & 14 & 24955 & 11 \\
\hline $65-74$ & 18042 & 24 & 10885 & 15 & 7472 & 11 & 1229 & 10 & 676 & 9 & 38304 & 16 \\
\hline $95+$ & 1272 & 2 & 4347 & 6 & 6953 & 10 & 1008 & 9 & 86 & 1 & 1366 & 6 \\
\hline \multicolumn{13}{|l|}{ Income† } \\
\hline Lowest & 16014 & 21 & 17288 & 24 & 15637 & 23 & 2545 & 22 & 2008 & 26 & 53492 & 23 \\
\hline Low & 15931 & 21 & 15344 & 21 & 13634 & 20 & 2317 & 20 & 1626 & 21 & 48852 & 21 \\
\hline Middle & 14698 & 19 & 13727 & 19 & 13059 & 19 & 2086 & 18 & 1474 & 19 & 45044 & 19 \\
\hline High & 14621 & 19 & 13074 & 18 & 12884 & 19 & 2063 & 18 & 1358 & 17 & 44000 & 19 \\
\hline Highest & 13996 & 19 & 12136 & 17 & 11850 & 18 & 1967 & 17 & 1258 & 16 & 41207 & 18 \\
\hline \multicolumn{13}{|l|}{ Rurality† } \\
\hline Urban & 64302 & 85 & 61171 & 85 & 57853 & 86 & 9752 & 83 & 6564 & 84 & 199642 & 85 \\
\hline 4 & 14238 & 19 & 11296 & 16 & 11059 & 16 & 1815 & 15 & 674 & 9 & 39082 & 17 \\
\hline 5 & 11260 & 15 & 11772 & 16 & 10730 & 16 & 1740 & 15 & 457 & 6 & 35959 & 15 \\
\hline $6+$ & 17081 & 23 & 27508 & 38 & 23547 & 35 & 3682 & 31 & 649 & 8 & 72467 & 31 \\
\hline
\end{tabular}

*Percentages of 'total cohort' row represent the proportion of the whole cohort. All other percentages in each descriptive category are representative of the proportion of patients in each category under each trajectory and are not summative across a whole row. †Does not equal $100 \%$ : a small number of records are missing this information. 


\section{Palliative care access}

Among the full cohort, $54 \%$ received at least one palliative care service in the last year of life. Palliative care from an institutional and community setting was mainly delivered by hospital inpatient services ( $46 \%$ of overall cohort) and community outpatient services $(25 \%)$, respectively. Palliative care physician home visits were delivered to $6 \%$ of the overall decedent cohort. However, there was wide variation in use of palliative care across end-of-life trajectories (table 2). Across all settings, $88 \%$ of those in the terminal illness trajectory received palliative care compared with $44 \%$ of the organ failure trajectory and $32 \%$ in the frailty trajectory. Within particular settings, the terminal illness trajectory had nearly twice as many decedents receiving palliative care services in the hospital inpatient setting $(76 \%)$ than the other trajectories. Many terminal illness decedents received outpatient palliative care $(53 \%)$ and end-of-life home care services (47\%), which was four and eight times more, respectively, than in the other two trajectories. Palliative care physician home visits were delivered to $15 \%$ of terminal illness decedents compared with $3 \%$ of organ failure decedents and $2 \%$ of frailty decedents.

\section{Intensity of palliative care}

Among users of palliative care in any setting, terminal illness has the highest mean number of palliative care days, ranging from 17 in an institution and 32 in the community,compared with 12 and 11 for organ failure and 11 and 10 for frailty trajectories. In all trajectories, about half of all palliative care days used occurred in the last 2 months of life, with a twofold increase in the last month of life. For example, decedents in the terminal illness trajectory averaged eight palliative care days in the second to last month before death, which increased to 13 days in the final month of life.

\section{Initiation of palliative care}

Decedents in the terminal illness trajectory had palliative care initiated a median of 107 days before death, more than four times earlier than organ failure (median 22 days) and frailty (median 24 days). In terms of intensity, the terminal illness trajectory had palliative care on $37 \%$ of days after initiation versus $25 \%$ and $23 \%$ in organ failure and frailty decedents (table 3).

\section{Multivariable analyses of odds of using any palliative care services}

When examining the odds of using any palliative care services in the last year of life, decedents with a terminal illness trajectory have an OR of 17.0 (OR 95\% CI 17.03 to 17.09) when compared with those with a frailty trajectory controlling for sex, age, income quintile, rurality and

Table 2 Use ( $\geq 1$ encounters) of palliative care by end-of-life trajectory and sector in the last year of life

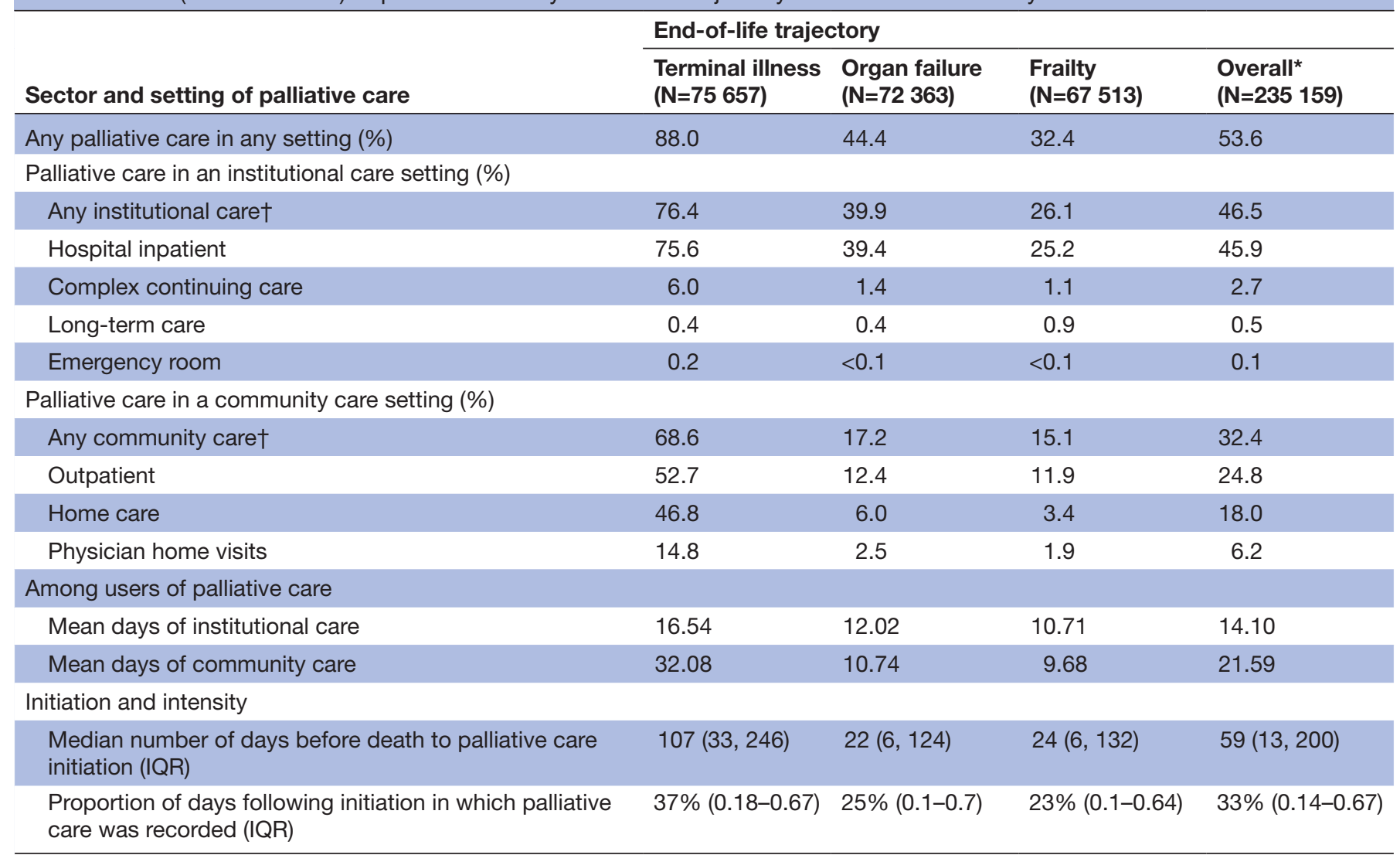

${ }^{*}$ Overall includes the sudden death (3\%) and other (5\%) trajectories which account for $8 \%$ of the total cohort. These are not individually shown here.

†Multiple services received on the same calendar day are counted as a single unit of 'Any community care' or 'Any institutional care'. This avoids double counting palliative care in a single day and prevents decedents from having more service days than total days. 
Table 3 Predictive models for the use of palliative care

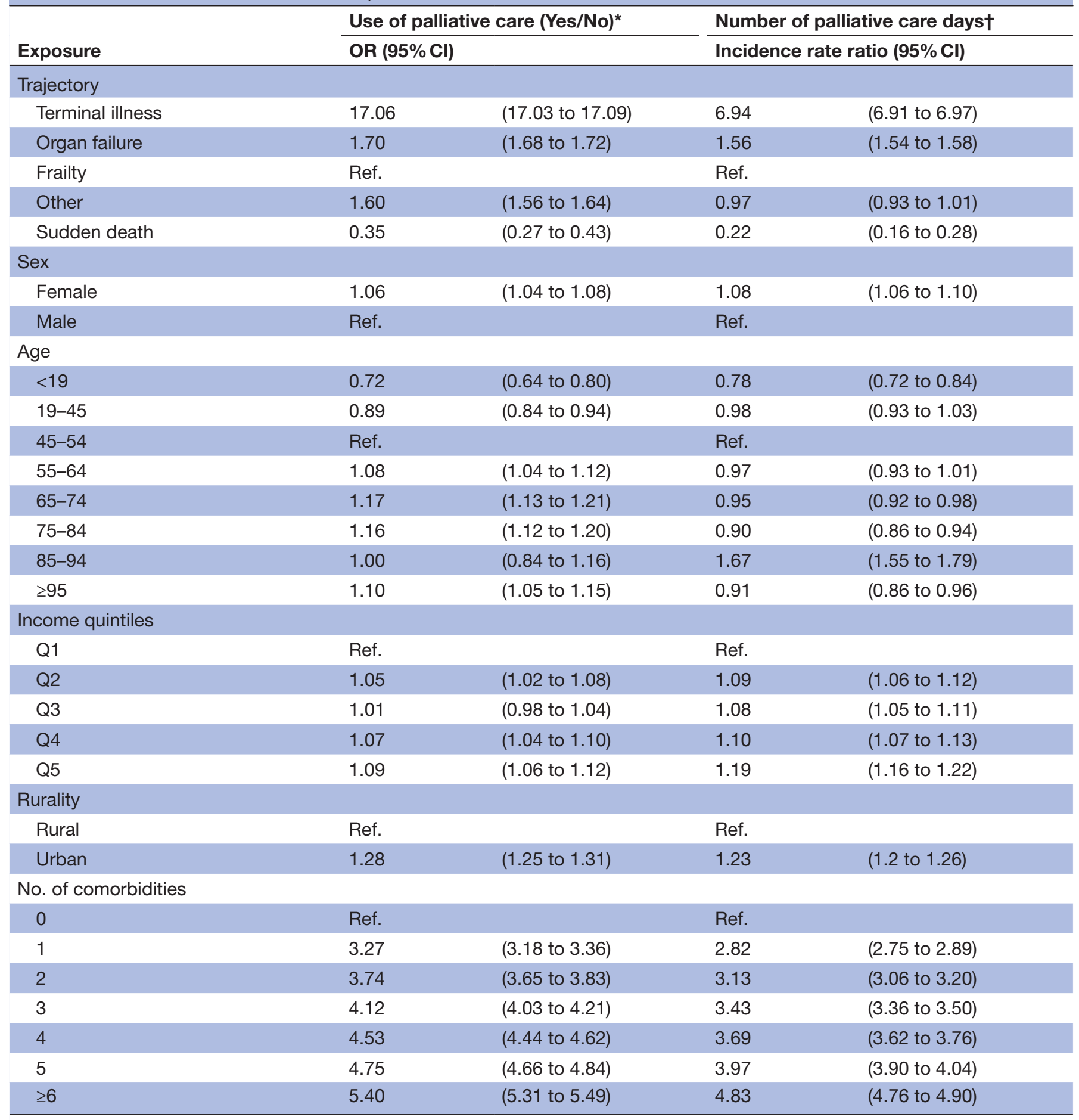

*Multivariable logistic regression was used to determine OR.

$\dagger$ Negative binomial regression was used to determine incidence rate ratio.

number of comorbidities (table 3). Decedents in the organ failure trajectory are nearly twice (OR 1.7, 95\% CI 1.68 to 1.72 ) as likely to use any palliative care compared with frailty trajectory.

\section{Multivariable analyses of number of palliative care days} received

Negative binomial regression analysis shows that decedents in the terminal illness trajectory receive seven times more days of palliative care (incidence rate ratio: 6.94, $95 \%$ CI 6.91 to 6.97 ) in the last year of life than decedents with a frailty trajectory. Increasing comorbidity was associated with higher number of days of palliative care received in the last year of life.

Comparison to palliative care access in other countries

In our cohort, among those who received any palliative care services, $55 \%$ died from terminal illness, $27 \%$ 
from organ failure and $18 \%$ from frailty illness trajectories. Whereas among those who received the Medicare Hospice Benefit in the USA, 27\% had cancer, $17 \%$ had dementia and $30 \%$ had cardiac, circulatory or respiratory failure $^{32}$ (table 4). Data from Western Australia shows $69 \%$ of patients with cancer and $14 \%$ of patients without had access to specialist palliative care services ${ }^{33}$ (compared with $88 \%$ of cancer and $39 \%$ non-cancer in Ontario, Canada). In UK, among palliative care inpatient admissions, $88 \%$ had cancer. ${ }^{34}$

Length of stay also varies by country. In Ontario, UK and Western Australia, patients with cancer had longer median lengths of stays (range 37-107 days) than other disease trajectories (range 6-43 days). ${ }^{33}$ However in the USA, the trend is the opposite, with patients with dementia having the longest median lengths of stay (56 days) and patients with cancer have the shortest (19 days). ${ }^{32}$

\section{DISCUSSION}

Our population-based analysis of decedents in Ontario, Canada shows that while nearly half of decedents receive at least one palliative care service, there are large disparities based on dying trajectory. Eightyeight per cent of those dying in the terminal illness trajectory (predominantly cancer deaths) received palliative care services compared with organ failure $(44 \%)$ or frailty trajectories $(32 \%)$. The terminal illness group also received twice as many palliative care services and four times earlier than the other two trajectories. In our universal insured hospital and physician system that does not require patients to forego curative treatment to receive palliative care, the median time from first palliative care service to death is 107 days for terminal illness, 22 days for organ failure and 24 days for frailty trajectories.

Our hypotheses were incorrect. While our Canadian data demonstrated terminal illness (predominantly cancer) patients received palliative care much earlier before death than in the USA, patients without cancer in Ontario were identified closer to death than in the USA. Importantly, the type of palliative care services offered, the training of providers and the organisation of the delivery system are not equivalent between countries or within Canada. ${ }^{35}$ Nonetheless, comparing similar statistics between geographic areas can generate hypotheses on how different eligibility criteria and health systems may explain differences in results. For instance, the in-home visiting hospice insured services offered in the USA includes extensive teams of specialist physicians and nurses and interprofessional providers, which is more comprehensive and coordinated than the services offered across Ontario, Canada. ${ }^{36}$ Indeed, our results show the vast majority of palliative care services were delivered in hospital inpatient units, not the home as in the USA. Yet the requirement to forego curative treatment to receive hospice care in the USA may be a factor in its relatively late initiation for patients with cancer, particularly with advancements in cancer treatment. Conversely, the comprehensive home-based focus of the US hospice insured benefit may explain the higher proportion of patients without cancer using it and for longer compared with Ontario, Canada which does not have widespread access to home-based fully insured palliative care teams.

Our data are also interesting compared with UK (universal health system) and Western Australia (mix of public and private health systems), which also have no requirements for an expected death certification or to forego curative treatments. Despite this similarity in eligibility, access to palliative care, use by disease trajectories, initiation before death and intensity and type of service use differ. The physician ratio is lower in Ontario, Canada than the other countries. The UK and USA have more physician specialists $(75 \%)$ to generalists $(25 \%)$ (all specialties) compared with Western Australia and Ontario, which is half-half. ${ }^{37}$ The availability of human resources and their training likely affects palliative care access and the delivery model (ie, specialist or generalist driven). For instance, in Ontario, one study showed that there were only 276 of 9732 family physicians, where palliative care services comprised more than $10 \%$ of their billings $(40 \%$ of the cohort billed no palliative care at all) ${ }^{38}$ Indeed receipt of physician home-based visits for palliative care was very low across all disease trajectories in our data, which may be related to inadequate billing fees for home visits. ${ }^{39}$ The limited availability of palliative care physician specialists may explain preferential access to patients with terminal illness, who may traditionally be easier to identify as needing palliative care. Considering the growing body of evidence of efficacious palliative care interventions for non-cancer diseases, ${ }^{17-20} 40$ the marked disparities in access to patients without cancer ought to be a policy priority and will likely require overcoming the stigma of imminent death and medical failure as well as education on the benefits of early integration. ${ }^{414}$

Limitations of using administrative health data to capture the use of palliative care include the potential undercoding of palliative care delivered, particularly in the community and long-term care. ${ }^{25}$ In the community, despite financial incentives to use specialised billing codes for palliative care, physicians may provide care reflecting palliative intent or elements of a palliative approach but not bill as such. This may include discussions about coping, basic symptom management and so on. In longterm care, palliative care billing codes are uncommon, rather, monthly management codes and subsequent visit codes are used. ${ }^{25434}$ There are potential issues with reliability and validity when using cause of death data to group decedents into disease trajectories, particularly with the non-terminal illness trajectories. For example, not all stroke recovery follow the trajectory pattern of organ failure. We cannot describe the quality of care or include services provided by volunteers, family members 


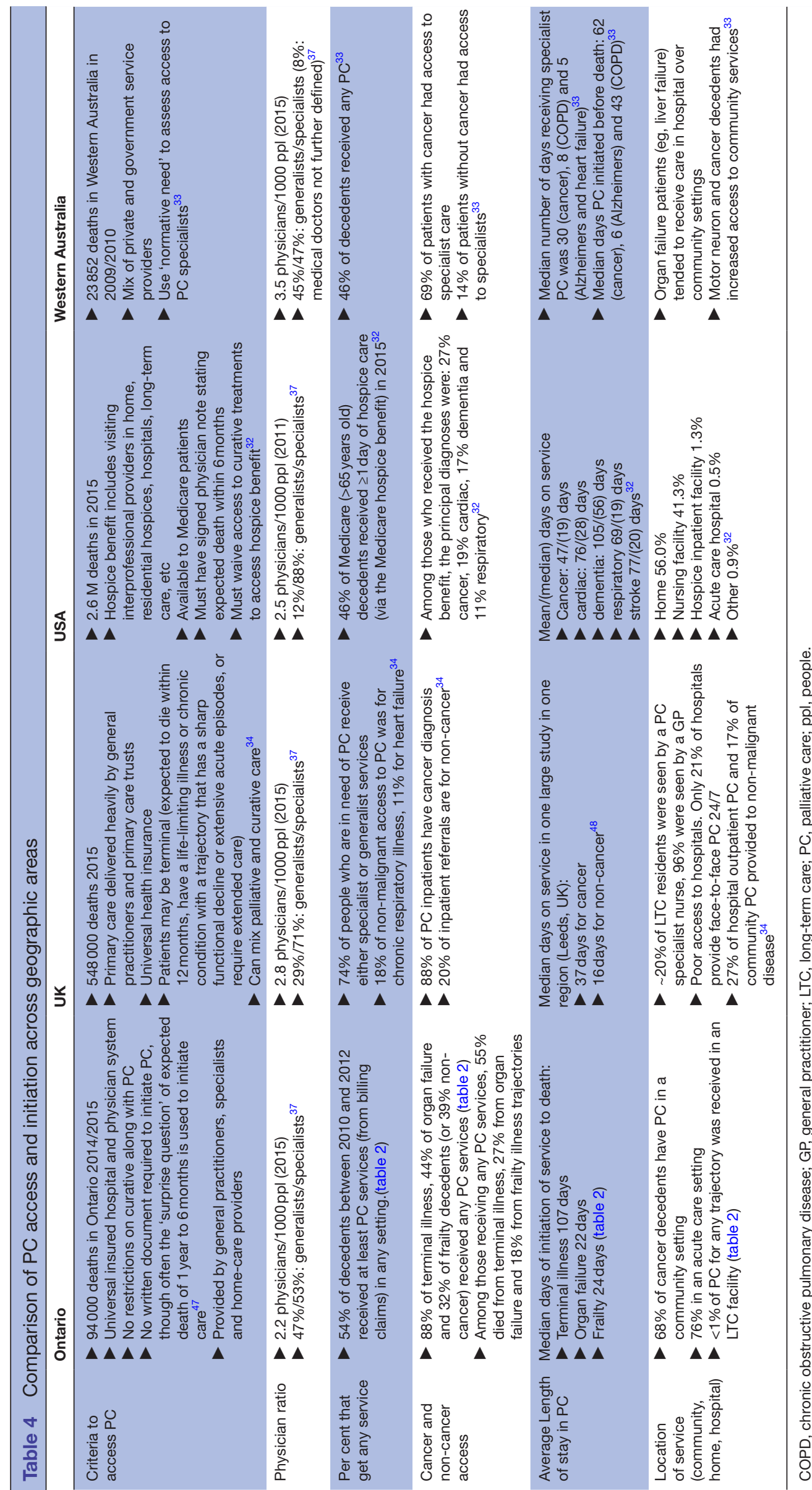


or private care that is not recorded in the health administrative databases. We also do not have an administrative database for hospice services and cannot account for care provided in a residential hospice. However, only $1 \%-3 \%$ of deaths occur in a residential hospice, and the majority of hospice care occurs after initiation of palliative home care services-which is included in our study.

In conclusion, our study quantifies a large disparity in access to palliative care for those dying from organ failure and frailty trajectories. Decedents with a terminal illness trajectory, exemplified by a cancer diagnosis, are significantly more likely to receive palliative care services than the other dying trajectories; they receive more services (intensity) both in hospital and community, and these services are initiated earlier in the dying trajectory. All trajectories could benefit from increased access to palliative home care services and physician home visits. This data will be useful to compare to in the future since a national palliative care framework was an identified need ${ }^{45}$ and has recently been passed into law. ${ }^{46}$ These data also serve as a useful comparison for other countries with similar and different healthcare systems and eligibility criteria to explore palliative care access across disease trajectories.

Contributors HS and PT conceptualised the study and RP performed the data abstraction and analysis. All authors contributed to interpretation and critical analysis of results. EO and HS drafted the first manuscript and all authors were responsible for contributing to the critical content and review of the manuscript. All authors act as guarantors and affirm that the article is an honest, accurate and transparent account of the study being reported; that no important aspects of the study have been omitted and that any discrepancies from this study as planned have been explained. All authors take responsibility for the integrity of the data and the accuracy of the data analysis.

Funding The author(s) disclosed receipt of the following financial support for the research, authorship and/or publication of this article. This research was supported by a research grant from the Ontario MOHLTC to the Health System Performance Research Network (HSPRN). This study was also supported by the ICES, which is funded by an annual grant from the Ontario MOHLTC. The opinions, results and conclusions reported in this article are those of the authors and are independent from the funding sources. No endorsement by MOHLTC is intended or should be inferred.

Disclaimer The funders had no influence in study design; in the collection, analysis and interpretation of data; in the writing of the report and in the decision to submit the article for publication.

Competing interests None declared.

Patient consent Not required.

Ethics approval This study has been approved by the research ethics board at the ICES, at Sunnybrook Health Sciences Centre in Toronto, ON, Canada and by the research ethics board at the Ottawa Hospital Research Institute at Ottawa, ON Canada.

\section{Provenance and peer review Not commissioned; externally peer reviewed.}

Data sharing statement Using encrypted health card numbers as unique identifiers, records of healthcare use and costs were linked across various administrative databases. No written consent was obtained; all data were encrypted using health card numbers as unique identifiers. Thus, all records used were deidentified and anonymised. All data were housed and analyses at ICES, a prescribed entity for the purposes of section 45 of Ontario's Personal Health Information Privacy Act.

Open Access This is an Open Access article distributed in accordance with the Creative Commons Attribution Non Commercial (CC BY-NC 4.0) license, which permits others to distribute, remix, adapt, build upon this work non-commercially, and license their derivative works on different terms, provided the original work is properly cited and the use is non-commercial. See: http://creativecommons.org/ licenses/by-nc/4.0/ (c) Article author(s) (or their employer(s) unless otherwise stated in the text of the article) 2018. All rights reserved. No commercial use is permitted unless otherwise expressly granted.

\section{REFERENCES}

1. Meier DE. Increased access to palliative care and hospice services: opportunities to improve value in health care. Milbank $Q$ 2011;89:343-80.

2. Morin L, Aubry R, Frova L, et al. Estimating the need for palliative care at the population level: a cross-national study in 12 countries. Palliat Med 2017;31:526-36.

3. Bakitas M, Lyons KD, Hegel MT, et al. The project ENABLE ॥ randomized controlled trial to improve palliative care for rural patients with advanced cancer: baseline findings, methodological challenges, and solutions. Palliat Support Care 2009;7:75-86.

4. Temel JS, Greer JA, Muzikansky A, et al. Early palliative care for patients with metastatic non-small-cell lung cancer. $N$ Engl J Med 2010;363:733-42.

5. Zimmermann C, Swami N, Krzyzanowska M, et al. Early palliative care for patients with advanced cancer: a cluster-randomised controlled trial. Lancet 2014;383:1721-30.

6. Amblàs-Novellas J, Murray SA, Espaulella J, et al. Identifying patients with advanced chronic conditions for a progressive palliative care approach: a cross-sectional study of prognostic indicators related to end-of-life trajectories. BMJ Open 2016;6:e012340.

7. Lunney JR, Lynn J, Foley DJ, et al. Patterns of functional decline at the end of life. JAMA 2003;289:2387-92.

8. Murray SA, Kendall M, Boyd K, et al. Illness trajectories and palliative care. BMJ 2005;330:1007-11.

9. Cantin B, Rothuisen LE, Buclin T, et al. Referrals of cancer versus non-cancer patients to a palliative care consult team: do they differ? J Palliat Care 2009;25:92-9.

10. Dalkin SM, Lhussier M, Philipson P, et al. Reducing inequalities in care for patients with non-malignant diseases: Insights from a realist evaluation of an integrated palliative care pathway. Palliat Med 2016;30:690-7.

11. Fassbender K, Watanabe SM. Early palliative care and its translation into oncology practice in Canada: barriers and challenges. Ann Palliat Med 2015;4:135-49.

12. Higginson IJ, Evans CJ. What is the evidence that palliative care teams improve outcomes for cancer patients and their families? Cancer J 2010;16:423-35.

13. Ornstein KA, Schulz $R$, Meier DE. Families caring for an aging America need palliative care. J Am Geriatr Soc 2017;65:877-8.

14. Walshe C, Todd C, Caress A, et al. Patterns of access to community palliative care services: a literature review. J Pain Symptom Manage 2009;37:884-912.

15. Murtagh FE, Preston M, Higginson I. Patterns of dying: palliative care for non-malignant disease. Clin Med 2004;4:39-44.

16. Oishi A, Murtagh FE. The challenges of uncertainty and interprofessional collaboration in palliative care for non-cancer patients in the community: a systematic review of views from patients, carers and health-care professionals. Palliat Med 2014;28:1081-98.

17. Brumley RD, Enguidanos S, Cherin DA. Effectiveness of a homebased palliative care program for end-of-life. J Palliat Med 2003;6:715-24.

18. Gomes B, Calanzani N, Curiale V, et al. Effectiveness and costeffectiveness of home palliative care services for adults with advanced illness and their caregivers. Cochrane Database Syst Rev 2013;6:CD007760.

19. Horton R, Rocker G, Dale A, et al. Implementing a palliative care trial in advanced COPD: a feasibility assessment (the COPD IMPACT study). J Palliat Med 2013;16:67-73.

20. Veronese S, Gallo G, Valle A, et al. Specialist palliative care improves the quality of life in advanced neurodegenerative disorders: NE$\mathrm{PAL}$, a pilot randomised controlled study. BMJ Support Palliat Care 2017;7:164-72

21. Dumont $S$, Jacobs $P$, Turcotte $V$, et al. Palliative care costs in canada: a descriptive comparison of studies of urban and rural patients near end of life. Palliat Med 2015;29:908-17.

22. Moss AH, Lunney JR, Culp S, et al. Prognostic significance of the "surprise" question in cancer patients. J Palliat Med 2010;13:837-40.

23. Anderson F, Downing GM, Hill J, et al. Palliative performance scale (PPS): a new tool. J Palliat Care 1996;12:5-11.

24. Statistics Canada. Table 102-0563, Leading casues of death, total population, by sex, Canada, provinces and territories (age standardization using 1991 population) annual (TABLE). CANSIM (Database). 2017 www5.statcan.gc.ca/cansim/a47. 
25. Tanuseputro P, Budhwani S, Bai YQ, et al. Palliative care delivery across health sectors: a population-level observational study. Palliat Med 2017;31:247-57.

26. Tanuseputro P. Delivering care to those in need: improving palliative care using linked data. Palliat Med 2017;31:489-91.

27. Statistics Canada. Annual demographic estimates: subprovincial areas. Ottawa, ON: Statistics Canada, 2010.

28. Gill TM, Gahbauer EA, Han L, et al. Trajectories of disability in the last year of life. N Engl J Med 2010;362:1173-80.

29. Canadian Institute for Health Information. Health care use at the end of life in atlantic Canada. Ottawa, ON: CIHI, 2011.

30. Fassbender K, Fainsinger RL, Carson M, et al. Cost trajectories at the end of life: the Canadian experience. J Pain Symptom Manage 2009;38:75-80.

31. Wilkins R. PCCF + version $3 g$ users guide: automated geographic coding based on the statistics canada postal code conversion files. cat. no. 82F0086-XDB. Ottawa: Statistics Canada, 2001.

32. National Hospice and Palliative Care Organization. NHPCO facts and figures: hospice care in America. Alexandria, Virginia: National Hospice and Palliative Care Organization, 2016. https://www.nhpco.org/sites/ default/files/public/Statistics_Research/2016_Facts_Figures.pdf.

33. Rosenwax L, Spilsbury K, McNamara BA, et al. A retrospective population based cohort study of access to specialist palliative care in the last year of life: who is still missing out a decade on? BMC Palliat Care 2016;15:46.

34. Dixon J, King D, Matosevic T, et al. Equity in the provision of palliative care in the uk: review of evidence. London, UK: London School of Economics and Political Science, 2015.

35. Williams AM, Crooks VA, Whitfield K, et al. Tracking the evolution of hospice palliative care in Canada: a comparative case study analysis of seven provinces. BMC Health Serv Res 2010;10:147.

36. Seow H, Barbera L, Pataky R, et al. Does increasing home care nursing reduce emergency department visits at the end of life? A population-based cohort study of cancer decedents. J Pain Symptom Manage 2016;51:204-12.
37. OECD. Health at a glance 2015: OECD indicators. Paris: OECD publishing, 2015

38. Barbera L, Hwee J, Klinger C, et al. Identification of the physician workforce providing palliative care in Ontario using administrative claims data. CMAJ Open 2015;3:E292-E298.

39. Pereira J, Chasen MR. Early palliative care: taking ownership and creating the conditions. Curr Oncol 2016;23:367-70.

40. Gómez-Batiste X, Murray SA, Thomas K, et al. Comprehensive and integrated palliative care for people with advanced chronic conditions: an update from several european initiatives and recommendations for policy. J Pain Symptom Manage 2017;53:509-17.

41. Collins A, McLachlan SA, Philip J. Initial perceptions of palliative care: an exploratory qualitative study of patients with advanced cancer and their family caregivers. Palliat Med 2017;31:825-32.

42. Zimmermann C, Swami N, Krzyzanowska M, et al. Perceptions of palliative care among patients with advanced cancer and their caregivers. CMAJ 2016;188:E217-E227.

43. Brazil K, Bédard $\mathrm{M}$, Krueger $\mathrm{P}$, et al. Barriers to providing palliative care in long-term care facilities. Can Fam Physician 2006;52:472-3.

44. Miller SC, Teno JM, Mor V. Hospice and palliative care in nursing homes. Clin Geriatr Med 2004;20:717-34.

45. Morrison RS. A national palliative care strategy for canada. J Palliat Med 2018;21(S1):S-63-60.

46. Bill C-277. An Act providing for the development of a framework on palliative care in Canada. http://www.parl.ca/DocumentViewer/en/ 42-1/bill/C-277/royal-assent.

47. Health Quality Ontario. Palliative care at the end of life. Toronto, Ontario: Queen's printer for Ontario, 2016.

48. Bennett MI, Ziegler L, Allsop M, et al. What determines duration of palliative care before death for patients with advanced disease? A retrospective cohort study of community and hospital palliative care provision in a large UK city. BMJ Open 2016;6:e012576. 